\title{
Single-stage laryngotracheal reconstruction for the treatment of subglottic stenosis in children
}

\section{Reconstrução laringotraqueal em único estágio para tratamento de estenose subglótica em crianças}

\author{
Mariana Magnus Smith ${ }^{1}$, Cláudia Schweiger ${ }^{2}$, Denise Manica ${ }^{3}$, Camila Degen Meotti ${ }^{4}$, Larissa Valency Eneas ${ }^{5}$, Gabriel Kuhl${ }^{6}$, \\ Paulo Jose Cauduro Marostica?.
}
1) Master. Medical Residency Preceptor of Otolaryngology of Hospital São Lucas of PUCRS / Sao Lucas Hospital of PUC/RS - Catholic University, Rio Grande do Sul State, Brazil.
2) Master. Medical Residency Preceptor of Otolaryngology of Hospital de Clínicas of Porto Alegre/Clinical Hospital of Porto Alegre, Rio Grande do Sul State, Brazil 3) Otolaryngologist. Fellowship in Laryngology of Hospital de Clínicas of Porto Alegre/ Clinical Hospital of Porto Alegre, Rio Grande do Sul State, Brazil.
4) Otolaryngologist. Fellowship em Rhinology of Hospital de Clínicas of Porto Alegre/ Clinical Hospital of Porto Alegre, Rio Grande do Sul State, Brazil.
5) Otolaryngologist. Medical Residency Preceptor of Otolaryngology of Hospital São Lucas of PUCRS/ Sao Lucas Hospital of PUC/RS - Catholic University, Rio Grande Do Sul State, Brazil.
6) Otolaryngologist. Professor of Otolaryngology and Ophthalmology Department of UFRGS. Medical Residency Preceptor of Otolaryngology of HCPA-Clinical Hospital of Porto Alegre.
7) Post-Ph.D. Professor of Pediatrics Department of UFRGS - Federal University of Rio Grande do Sul State. Medical Residency Preceptor of Pediatrics of HCPA - Clinical Hospital of Porto Alegre.

Institution: Hospital of Clinicas de Porto Alegre.

Porto Alegre / RS - Brazil.

Mailing address: Cláudia Schweiger - Ramiro Barcelos Street, 2350 - Zona 19 - Porto Alegre / RS - Brazil - Zip-code: $90035-903$ - E-mail: causch@ hotmail.com Article received in September 7, 2011. Article approved in October 12, 2011.

\section{SUMMARY}

Introduction: In recent decades, airway reconstruction has become the treatment of choice for subglottic stenosis (SGS) in children, which is performed in either single or multiple stages. However, there is evidence in the literature that singlestage surgery is more effective.

Objective: To evaluate the success rate of single-stage laryngotracheoplasty (LTP) and cricotracheal resection (CTR) in patients that were treated in our hospital. Materials and Method: We performed a retrospective study of children undergoing laryngotracheal reconstruction.

Results: Twenty-four children were included. The etiology of SGS was postintubation in $91.6 \%$ and congenital in $8.3 \%$. One patient (4.2\%) had grade 4 SGS, $17(70.8 \%)$ presented with grade 3 SGS, 4 (16.6\%) had grade 2 SGS, 1 (4.2\%) had grade 3 SGS associated with glottic stenosis, and 1 (4.2\%) had grade 3 SGS with tracheal stenosis. We performed 26 LTPs and 3 CTRs. Decannulation rates were $66 \%$ in the CTR procedures and $85.7 \%$ in the LTP procedures; the overall decannulation rate was $83.3 \%$. All children presented with fever in the postoperative period, but were afebrile after the tube was removed.

Conclusion: Our series showed a decannulation rate of $83.3 \%$. Keywords: larynx, child, laryngostenosis.

\section{RESUMO}

Introdução: Nas últimas décadas, a reconstrução da via aérea tornou-se o tratamento de escolha para estenose subglótica (ESG) na criança, realizada em único ou múltiplos estágios. Há indícios na literatura de que a cirurgia em um só tempo é mais efetiva.

Objetivo: Avaliar o índice de sucesso da laringotraqueoplastia (LTP) e ressecção cricotraqueal (RCT) em único estágio nos pacientes tratados no nosso hospital.

Método: Estudo retrospectivo de crianças submetidas à reconstrução laringotraqueal.

Resultados: Foram incluídos 24 pacientes. As causas da ESG foram pós-intubação endotraqueal em 91,6\% e congênita em 8,3\%. Diagnosticamos ESG grau 4 em 1 paciente (4\%), grau 3 em 16 (66,6\%), grau 2 em 4 (16,6\%), grau 3 associada com estenose glótica em 1 (4\%), grau 3 associada com estenose traqueal em 1 (4\%). Foram realizadas 26 LTP e 3 RCT. O índice de decanulação foi de $66 \%$ nos pacientes submetidos à RCT e de $85,7 \%$ nos pacientes submetidos à LTP; o índice total de decanulação foi de 83,3\%. Todos apresentaram febre persistente no pós-operatório, que cessou após a extubação.

Conclusão: Nossa série mostrou índice de decanulação de 83,3\%.

Palavras-chave: laringe, criança, laringoestenose. 


\section{INTRODUCTION}

Over the last 3 decades, airway reconstruction has become the treatment of choice for subglottic stenosis (SGS) in children. Two surgical procedures are commonly used in the management of SGS: laryngotracheoplasty (LTP), in which a cartilage graft is used to expand the luminal diameter of the airway, and cricotracheal resection (CTR), in which the stenosed segment is resected and an end-to-end anastomosis is performed.

LTP was first described by Evans and TODD (1) in 1974 , but gained popularity with Cotton in the late 70 s with the widespread use of costal cartilage grafts (2). CTR is the preferred option for children with severe stenosis (MyerCotton grades III and IV) (3).

Laryngotracheal reconstruction can be performed at a single stage, using the endotracheal tube (ETT) as a temporary stent after surgery, or in multiple stages, with a tracheostomy inserted (if not already in place) to safeguard the airway postoperatively. There is evidence in the literature that the single-stage procedure is more effective, as the ETT is used as a stent of the airway, which also helps to prevent obstructive granulation $(10,11)$.

Single-stage laryngotracheal reconstruction has become a worldwide trend, and it is our treatment of choice for patients undergoing open surgery for SGS.

Our aim was to evaluate the success rate of singlestage LTP and CTR procedures that were performed in pediatric patients in our hospital, to describe the characteristics of our sample, and to compare our results to those reported in the literature.

\section{MeTHOD}

We performed a retrospective study by reviewing the medical records of patients who underwent laryngotracheal reconstruction in the period between June 2005 and November 2009. We included all pediatric patients with laryngeal and/or proximal tracheal stenosis who underwent a single-stage procedure.

The project was approved by the Ethics Committee of our hospital (approval \#09-568). The data were analyzed with PASW 17.0. Below, we describe the procedures in detail.

\section{Single-stage LTP}

Patients were intubated, unless a tracheostomy tube was present, in which case they were ventilated through the tracheostomy during surgery. Patients were positioned in cervical hyperextension, and the operative sites (anterior cervical region and costal cartilage) were infiltrated with a $1 \%$ lidocaine solution containing epinephrine $(1: 100,000)$.

The thorax was approached first, while minimizing the risk of contamination. The costal graft ( 2 to $3 \mathrm{~cm}$ in length) was taken from the right submammary region, which is adjacent to the osteocartilaginous junction, with a dissection performed close to the subperichondrial plane.

A horizontal cervical incision was made and a subplatysmal flap was created, thus exposing the cricoid and thyroid cartilage and the trachea. Next, an anterior midline laryngofissure was performed. At this stage, a posterior cricoid split may be performed, if indicated (if posterior grafting is needed). Then, if the patient underwent translaryngeal intubation, the endotracheal tube was advanced distal to the stenotic segment. The stenotic area was measured and the graft was fashioned in a fusiform shape (Figure 1). The perichondrial surface of the cartilage graft was positioned to face the lumen of the airway, and the graft was sutured with 5-0 polidioxanone into the posterior wall (Figure 2). A nasotracheal tube was introduced and left in place as an airway stent. If necessary, another costal cartilage graft was placed anteriorly. A Penrose drain was placed and the wound was closed in layers, including a prior tracheostomy, if present.

\section{CTR}

Usually there was a tracheostomy in situ (SGS Grade 4) and the ETT was inserted through the stoma. The patient was positioned in cervical hyperextension, and a local anesthetic solution was injected in the cervical incision sites. An elliptical incision was made around the tracheostomy and a subplatysmal flap was raised above the hyoid bone. An inferior subplatysmal flap was elevated down to the sternal notch (depending on the location and the extent of the stenosis). The airway was opened with a vertical midline incision through the cricoid cartilage and the stenosed area was examined. The upper resection margin was defined according to the stenosis (for example, if there was a need to remove a portion of the cricoid cartilage, the resection was extended laterally along the lower border of the thyroid towards the cricothyroid joint). The trachea was mobilized, keeping it as close as possible to the tracheal wall in the subperichondrial plane. To elevate the trachea, two 2-0 Prolene stay sutures were 


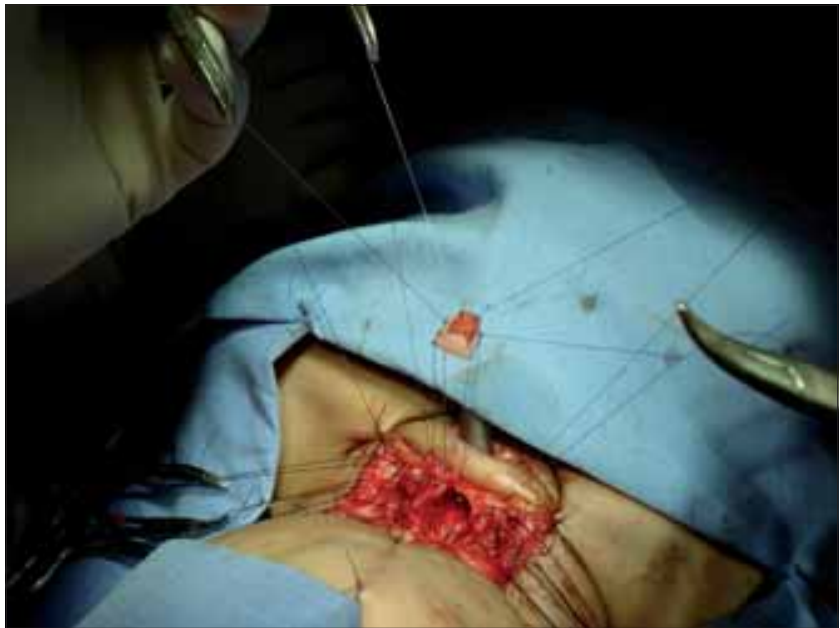

Figure 1. Placed on the suture costal cartilage graft and the posterior wall of the cricoid (laryngofissure later), before the definitive positioning of the graft. Note that the endotracheal tube, placed in the tracheostoma, below the area of stenosis.

inserted laterally into the tracheal wall. The lower resection margin must contain a full-sized, healthy tracheal ring. The neck was returned to the anatomical position and a nasotracheal tube was inserted. An endto-end anastomosis was performed using a 2-0 PDS suture. The wound was closed in layers over a Penrose drain.

In both LTP and CTR, the patient was referred to the Pediatric Intensive Care Unit (PICU) after surgery, where he/she remained intubated and sedated. On the 7 th postoperative day, direct fiber optic laryngoscopy was performed, after removing the ETT for visualization of the entire airway. If the operated area was patent, without abundant granulation tissue, and the graft was well placed (from the LTP), the patient was reintubated under direct visualization; sedation was reduced and the process of extubation began. On the 7 th day after extubation, a new direct laryngoscopy was made; if the airway was patent and the patient was asymptomatic, the child was released home and scheduled to return for outpatient followup. If necessary, children underwent additional procedures, such as dilatation, CO2 laser ablation, reintubation, and/or tracheostomy.

\section{RESULTS}

We reviewed the charts of 24 patients, aged 2 months to 17 years, who underwent LTP or CTR for correction of subglottic and/or tracheal stenosis.

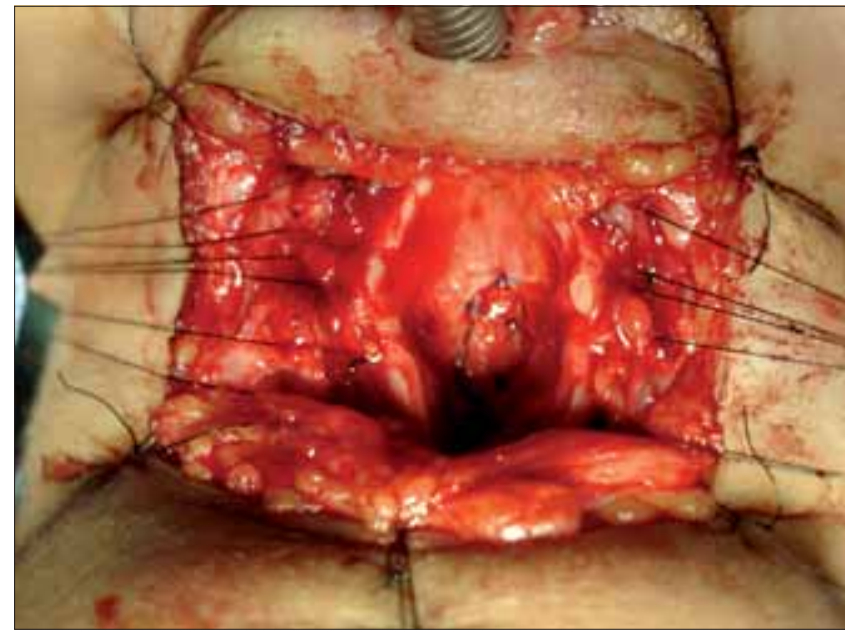

Figure 2. Laryngofissure later viewing with costal cartilage graft sutured with PDS 5.0. Note the wires mononylon for removal of the walls of the cricoid and trachea during surgery, auxiliary dispensing and placing spacers which may reflect these structures.

\section{Sample characteristics}

Thirteen patients (54\%) were male. Of the 24 patients, 17 (71\%) had no comorbidities. Comorbidities found in the other patients included prematurity (3 patients), epilepsy (1 patient), Fraser syndrome (1 patient) Down syndrome (1 patient), and biliary atresia (1 patient).

The etiology of SGS was endotracheal intubation in 22 patients (91.6\%) and congenital in 2 patients (8.3\%).

Among the patients in whom stenosis was caused by endotracheal intubation, the average number of days of intubation was 11.7, ranging from 5 to 28 days. Underlying pathology leading to intubation included the following: bronchiolitis in 7 patients (31.8\%), pneumonia in 2 patients (9\%), whooping cough in 2 patients (9\%), trauma in 3 patients (13.6\%), viral encephalitis in 1 patient (4.5\%), sepsis in 1 patient (4.5\%), disorders related to prematurity in 2 patients (9\%), meconium aspiration in 1 patient (4.5\%), tracheomalacia in 1 patient (4.5\%), pulmonary tuberculosis in 1 patient (4.5\%), and postoperative complications of other surgeries in 1 patient (4.5\%).

Preoperatively, the classification of SGS was the following: grade 4 SGS in 1 patient (4\%), grade 3 SGS in 16 patients (66.6\%), grade 2 SGS in 4 patients (16.6\%), grade 3 SGS associated with glottic stenosis in 1 patient (4\%), and grade 3 SGS associated with tracheal stenosis in 1 patient (4\%). 
Before definitive surgery, 18 patients (75\%) required tracheostomy for respiratory dysfunction.

Except for the insertion of the tracheostomy, LTP was the primary treatment in 19 patients (79.1\%). For 3 patients (12.5\%), CTR was the primary treatment, whereas carbon dioxide laser was the initial treatment of choice for 2 patients (8.3\%).

In total, 26 LTP procedures were performed (21 primary and 5 reinterventions). With respect to the grafts, posterior grafts were placed in 9 surgeries $(34.6 \%)$, anterior grafts in $2(7.7 \%)$, and associated grafts (anterior and posterior) were placed in 15 procedures $(57.7 \%)$.

There were no reported complications during surgery. Postoperative complications included 2 cases of pneumonia, 1 internal jugular vein thrombosis, 1 graft displacement, and 1 death from septic shock. The patient who had a displaced graft underwent reinterventions on the 14 th postoperative day, 7 days after extubation from the initial surgery.

The average period of postoperative intubation was 7.7 days.

All patients had persistent fever while in the PICU. After extubation, fever ceased in all of them. We performed a laboratory investigation for fever, but an infectious etiology was found in only 3 cases, including 2 patients with pneumonia and 1 with septic shock (and death).

\section{Success rates}

Among the 24 patients, 15 (62.5\%) had a satisfactory airway after the initial laryngotracheal reconstruction; 12 patients did not have stenosis and 3 had asymptomatic grade 1 SGS. These patients were decannulated, and showed no subsequent need for reintervention.

Five patients underwent reintervention (2nd LTP, CTR, carbon dioxide laser, or balloon dilation); all patients reestablished an adequate subglottic lumen and were decannulated after this 2 nd procedure.

Three patients underwent tracheostomy after the initial surgery because of restenosis. A reintervention has not been undertaken yet.

One patient died postoperatively due to septic shock and was considered a failure for the purposes of this study.
All direct laryngoscopies performed in the PICU on the 7 th postoperative day showed a patent airway, with little or no amount of granulation tissue, thus allowing the patients to be extubated following the procedure.

The decannulation rate was $66 \%$ in patients undergoing CTR and $85.7 \%$ in patients undergoing LTP . The overall decannulation rate was $83.3 \%$.

\section{DISCUSSION}

The management of laryngotracheal stenosis is a challenge for otolaryngologists, especially in the pediatric population. They are often complex cases, in which several treatment modalities are needed for the complete resolution of the problem. Various aspects should be taken into account, including the type, location, and extent of the stenosis, the degree of airway obstruction, the presence of vocal cord impairment, and the patient's neurological status.

A variety of surgical interventions are available for the management of SGS, including endoscopic laser with or without balloon dilatation or stent placement, balloon dilation angioplasty, LTP with anterior, posterior, or combined costal cartilage graft, either in single or multiple stages, and CTR. In this study, we described the results of our experience with single-stage techniques of LTP and CTR while using the ETT as an airway stent postoperatively in patients with subglottic and tracheal stenosis.

The etiology of the stenosis was postintubation in $91.4 \%$ of patients, which is in agreement with previous studies reporting that $90 \%$ of patients with acquired subglottic stenosis have a history of tracheal intubation (4); $8.6 \%$ of patients had congenital stenosis, compared to an incidence of approximately $5 \%$ that was reported in the literature (5).

Reports from other studies have shown decannulation rates ranging from $84 \%$ to $96 \%$ after singlestage LTP (6). In cases of CTR, decannulation rates range from $91 \%$ to $95 \%$ (7). In our series, the overall decannulation rate was $83.3 \%$. When analyzed separately, patients undergoing CTR had a decannulation rate of 66\%; compared to the literature, this lower rate was likely due to the small number of patients undergoing CTR in our series. It is important to note that until the end of the 90s, CTR was reserved mostly for adults (8); therefore, it is a relatively new surgical procedure in the pediatric population. When we analyzed only the LTP results, our decannulation rate was $85.7 \%$, which is comparable to that reported by other authors. 
Until about a year ago, we did not use balloon dilatation (with an angioplasty catheter) in the postoperative period of patients undergoing laryngotracheal reconstruction. When we started using this device, we noticed greater ease in managing subglottic granulation in these patients. Balloon laryngoplasty may thus increase our success rates in laryngotracheal reconstruction, since the 4 patients in our series who presented with restenosis would have undergone dilation after surgery, when they still had granulation tissue, which could have altered the outcome.

All direct laryngoscopies that were performed on the 7 th postoperative day showed a satisfactory airway, which allowed patients to be extubated; this has led us to reconsider the necessity of this procedure prior to extubation.

Postoperative fever seems to be common after airway reconstruction. A study conducted by Schraff et al. in 2010 showed that 59\% of patients who underwent single-stage LTP had fever postoperatively; however, fever was considered significant (with positive cultures) in only $1 / 3$ of the cases (9). In our sample, all patients had postoperative fever, which ceased after removal of the ETT. Nevertheless, the implications and the need to investigate and treat postoperative fever in laryngotracheal reconstructions are not yet established.

We will continue analyzing, now prospectively, data from pediatric patients undergoing CTR and LTP in our department, and we will continue testing the balloon technique for the treatment of restenosis after laryngotracheal reconstruction surgery.

Further studies are needed to determine the causes of therapeutic failures and to improve the postoperative management of these children.

\section{CONCLUSION}

We present our series of 24 children with laryngotracheal stenosis who underwent single-stage airway reconstruction. Our overall decannulation rate with LTP and CTR was $83.3 \%$.

\section{BiblogRAPHIC REFERENCES}

1. Koempel JA, Cotton RT. History of Pediatric Laryngotracheal Reconstruction. Otolaryngol Clin North Am. 2008, 41:825-35.

2. Cotton RT. Management of subglottic stenosis in infancy and childhood. Review of a consecutive series of cases managed by surgical reconstruction. Ann Otol Rhinol Laryngol. 1978, 87:649-57.

3. Myer CM III, O'Connor DM, Cotton RT. Proposed grading system for subglottic stenosis based on endotracheal tube sizes. Ann Otol Rhinol Laryngol. 1994, 103:319-23.

4. Boardman SJ, Albert DM. Single-Stage and Multistage Pediatric Laryngotracheal Reconstruction. Otolaryngol Clin North Am. 2008, 41:947-58.

5. Schroeder JW, Holinger LD. Congenital Laryngeal Stenosis. Otolaryngol Clin North Am. 2008, 41:865-75.

6. Gustafson LM, Hartley BEJ, Liu JH et al. Single-stage laryngotracheal reconstruction in children: A review of 200 cases. Otolaryngol Head Neck Surg. 2000, 123:430-4.

7. Sandu K, Monnier P. Cricotracheal Resection. Otolaryngol Clin N Am. 2008, 41:981-98.

8. Hartley BEJ, Cotton RT. Paediatric airway stenosis: laryngotracheal reconstruction or cricotracheal resection? Clin Otolaryngol. 2000, 25:342-9.

9. Schraff SA, Brumbaugh C, Meinzen-Derr J, Willging JP. The significance of post-operative fever following airway reconstruction. Int J Pediatr Otorhinolaringol. 2010, 74:5202.

10. Cotton RT. Management of laryngotracheal stenosis and tracheal lesions including single stage laryngotracheoplasty. Int J Ped Otorhinolaryngol. 1995, 32(Supplem):89-91.

11. Cotton RT, Myer CM III, O'Connor DM, et al. Pediatric laryngotracheal reconstruction with cartilage grafts and endotracheal tube stenting: the single-stage approach. Laryngoscope. 1995, 105:818-21. 